\title{
REVIEW ARTICLE Death investigation systems and disease surveillance
}

\author{
C. R. MCGOWAN ${ }^{1 *}$ AND A. M. VIENS ${ }^{2}$ \\ ${ }^{1}$ Faculty of Public Health \& Policy, London School of Hygiene \& Tropical Medicine, University of London, \\ London, UK \\ ${ }^{2}$ School of Law, Queen Mary, University of London, London, UK
}

(Accepted 10 November 2010; first published online 15 December 2010)

\section{SUMMARY}

Medico-legal death investigation systems have the potential to play an important role in disease surveillance. While these systems are in place to serve a public function, the degree to which they are independent of central government can vary depending on jurisdiction. How these systems use this independence may present problems for public health initiatives, as it allows death investigators to decline to participate in government-led surveillance regardless of how critical the studies may be to public health and safety. A recent illustration of this problem in the UK is examined, as well as general lessons for removing impediments to death investigation systems participating in public health research.

Key words: Creutzfeldt-Jakob disease (CJD), death investigation, public health, surveillance.

\section{Introduction}

In most developed countries there is a system in place for investigating both cause and circumstances of sudden and/or unexplained deaths. In nearly all such jurisdictions death investigation is a statutory function and is inherently both medical and legal in scope. Generally, the determination of the cause of death is a strictly biomedical issue, while a determination of the circumstances of death is based upon an investigative process defined under the law.

Death investigation, beyond fulfilling the purely legal requirement that deaths be appropriately certified, has the potential to contribute a great deal to disease surveillance (for both cause-specific and allcause mortality) and public health research [1-5]. Many death investigations require the collation of

* Author for correspondence: C. R. McGowan, Faculty of Public Health \& Policy, London School of Hygiene \& Tropical Medicine, 15-17 Tavistock Place, London WC1H 9SH, UK.

(Email: Catherine.McGowan@1shtm.ac.uk) an individual's social, behavioural and medical history in addition to standard demographic data. This documentation, in addition to information collected at the post-mortem examination, has the potential to yield important data, not only relating to mortality, but to morbidity as well.

Medico-legal post-mortems are performed at the request of the principal death investigator and do not require consent. They are intended to ascertain those facts pertaining to the death that are directly related to the death investigation process defined in law. Consented post-mortems are conducted at the request of the deceased in advance of their death, or by the next-of-kin; these investigations are not limited to the ascertainment of the cause of death and may instead focus on understanding disease processes and the effects of clinical intervention. The recent decline in consented post-mortems has been well documented in the literature $[6,7]$. In most countries the number of medico-legal post-mortems performed vastly 
outweighs that of consented procedures. Thus, death investigators may have jurisdiction over a proportionately large number of bodies thereby making these investigators an essential point-of-contact for researchers requiring access to post-mortem information and/or material.

Death investigation systems, which operate under the purview of a government department, may be required by the director or minister to participate in government-led research projects. However, when a death investigation system is located outside of central government, and is afforded the sort of independence normally reserved for the judiciary, it may be the prerogative of the death investigator to decide if $\mathrm{s} /$ he will participate. Thus, the viability of a disease surveillance study often does not depend upon the feasibility of the study itself; it is contingent on the willingness of the death investigator to participate or the government's ability to direct such participation [8].

\section{The importance of disease surveillance and post-mortem tissue to public health and safety}

Disease surveillance is absolutely essential to controlling threats to public health and safety. It is the primary means of: measuring the impact of these threats, detecting changes in incidence and prevalence, monitoring preventive and control measures, highlighting intervention priorities, building evidence for costing studies and providing aetiological clues about emergent diseases [9]. Complete and accurate reporting is essential in situations involving bioterrorism-related agents [10] and

highly contagious diseases for which contact tracing is required, serious infections such as botulism and rabies; and some new diseases such as variant CJD, very rare diseases which are not necessarily preventable, but for which more information is required, and conditions for which public health measures such as quarantine/isolation, chemoprophylaxis, vaccination or immunoglobulin are necessary $[9$, p. 15].

Some disease surveillance initiatives rely either entirely or in part on material collected at post-mortem. The vast majority of post-mortems are performed as part of a medico-legal death investigation and are done so under the direction of the principal death investigator (e.g. the coroner) who effectively has dominion over post-mortem data and tissue (including documentation pertaining to the death). In England and Wales, for example, more than $95 \%$ of postmortems are performed at the request of the coroner which, in 2009, represented 105354 post-mortem examinations $[6,11]$.

Disease surveillance studies (including prevalence surveys), which are intended to measure the prevalence of rare conditions, may be particularly dependent upon data from medico-legal post-mortems as large sample sizes are crucial to the precision of prevalence estimates. As consented post-mortems generally show a skewed age distribution they may be entirely unsuitable for surveillance studies that rely on a representative sample. Thus, the participation of the death investigator becomes integral to the implementation of any large-scale disease surveillance programme based upon post-mortem data requiring a representative sample.

Elsewhere it has been suggested that the advancement of public health and safety is one of the main purposes of a medico-legal death investigation [2, 4, 12-14]. This fact is evident in the many disease surveillance studies that have been successfully implemented within death investigation systems. For example, systems in the USA have participated in various public health and safety initiatives including: the Medical Examiner and Coroner Alert Project (involving fatalities and commercial products), the Drug Abuse Warning Network, the Fatal Accident Reporting System, Census of Fatal Occupational Injuries, the Food and Drug Administration's adverse drug and medical device fatality reporting system, and the National Violent Death Reporting System [2, 4]. In England and Wales, a few individual coroners have sought consent from families to retain DNA for a sudden arrhythmic death syndrome study [15] and, in Scotland, the chief procurators fiscal agreed to participate in the Medical Research Council's Sudden Death Brain and Tissue Bank project [16].

\section{Independence of death investigation systems}

While many disease surveillance studies are initiated by central government, the implementation of these initiatives is often delegated to other government agencies or to subordinate levels of government. In 1993, for example, the Minster of Health and the Attorney General for British Columbia, Canada appointed the Chief Coroner to conduct an inquiry into heroin-associated deaths in the province, which resulted in the ground-breaking and controversial Report of the Task Force Into Illicit Narcotic Overdose Deaths in British Columbia [17]. Cooperation between government officials is expected and, indeed, 
necessary for the execution of such studies. Thus, if central government administers a death investigation system, there are few barriers to implementing disease surveillance programmes beyond issues of funding and feasibility. The same is not true for systems of death investigation that are outside of the direction of central government. When a public organization, such as a death investigation system, is largely independent from government control, there are few means through which government can compel such organizations to participate.

Death investigation systems can take various forms - depending on the jurisdiction - and can be administered by a coroner, medical examiner or procurator fiscal, as well as by the military or police. These systems may vary in terms of, for example, the qualifications of the primary investigator, the method by which the relevant information about a death is determined, and the means through which the system maintains legitimacy. Death investigation systems maintain different degrees of independence from central government. Some systems afford paramount value to substantive independent inquiry (e.g. England, Wales, Northern Ireland, the Republic of Ireland, Hong Kong, Singapore, Jamaica), situating the death investigation system within the judicial branch. Other systems, particularly medical examiner systems in North America (e.g. Alaska, Alberta, Delaware, Manitoba, North Carolina, Nova Scotia, Tennessee, Utah, Vermont, Virginia, West Virginia), are afforded procedural independence, although the executive and/or legislative branches of government retain a considerable degree of administrative control.

In England and Wales, coroners consider themselves independent judicial officers whose allegiance lies not with government but with the Crown. Their appointment and remuneration is the responsibility not of central government, but of local authorities [18]. The coronial system relies on the formal inquest as the primary method through which the cause and circumstances of deaths are determined. In systems such as this, and in many derivative coronial systems, the primary death investigator is generally a lawyer or, in some cases, a judge who presides over the inquest, which is conducted in a court setting. The justification for treating coroners as independent judicial officers is that it constitutes an important safeguard for society and its citizens (i.e. it offers an independent investigation of deaths precipitated by state officials or in state custody) [18]. In England and Wales, however, the executive or legislative branches of government have no authority to instruct the death investigator in matters pertaining to the investigation, or to require that they participate in disease surveillance programmes or public health research.

An alternative to near absolute independence from government is a death investigation system situated within a government department or ministry. In these systems the death investigator's statutory function the investigation of the cause and circumstances of reported deaths - is provided substantive independence from central government. The investigator's non-statutory functions are, however, subject to oversight by the ministry or department through which they are administered. The primary death investigator is considered a 'quasi-judicial investigator' and conducts investigations 'independent from all law enforcement agencies and health authorities' [19]. In such systems, the ministry has the authority to direct the Chief Coroner/Medical Examiner to implement policies provided they do not compromise the death investigator's independence when it comes to the execution of the death investigator's statutory function. In addition, when a death investigation system falls under the auspices of a government department it is bound by the mandate of that department or ministry, which imposes a certain duty on the investigator particularly when that mandate, for example, explicitly implies a duty to 'protect the living' [20]. Under such death investigation systems, it is much more likely that disease surveillance programmes can be successfully implemented and that public health and safety will be promoted.

\section{The abnormal prion protein survey in England and Wales}

One recent example from the UK provides a poignant illustration of how important, well-intentioned and sufficiently funded public health initiatives can fall victim to a death investigation system that puts its independence from government ahead of protecting public health and safety.

In light of new evidence that variant CreutzfeldtJakob disease (vCJD) had the potential to emerge as a second-wave infection resulting from humanto-human transmission, the UK Health Protection Agency (HPA) proposed the creation of a postmortem tissue archive to study the prevalence of abnormal prion protein (a marker for VCJD infection) in the UK [21]. The study required tissue from a large 
number of post-mortems, necessitating the participation of coroners in England and Wales. Following a protracted correspondence of over a year-and despite efforts by the HPA to accommodate the coroners' concerns - the Coroners' Society of England and Wales (CSEW) declined to participate in the study, citing various issues including its putative legality, cost and feasibility. The CSEW concluded that to participate in the study would, 'adversely affect the independence of the coronial service and would further erode public confidence' [22].

Elsewhere, we have argued that concerns over the study's legality, cost and feasibility were misplaced [23]. The HPA and Chief Medical Officer provided the CSEW with ways to participate in the study that would alleviate or mitigate such concerns. The driving consideration appeared to be the CSEW's concern that an agency of central government was attempting to direct them in the conduct of their duties, and that efforts to have them participate in this research project posed a threat to coronial independence. Without the participation of coroners, this study has become entirely unfeasible, as there is no other realistic way to obtain the necessary tissue. The HPA, and other government committees, such as the Spongiform Encephalopathy Advisory Committee, continue to try to find ways of conducting further research to determine the prevalence of abnormal prion protein in the UK population; however, all subsequent options are methodologically inferior to the study as it was originally proposed.

One of the primary reasons given for the importance of coronial independence in modern times stems from the coroner's role in meting out the government's procedural obligation under Article 2 of the European Convention on Human Rights (ECHR) to protect the right to life. What is problematic is that it appears the CSEW has interpreted this obligation in negative terms, and seems to view any direction from a government agency as a possible threat to its independence. Given that government policy in the UK was deemed complicit, at least in part, in the initial outbreak of VCJD [24], and that the proposed vCJD study was intended to control the spread of iatrogenic infection through medical and dental procedures made available by the state, it could reasonably be argued that the vCJD study also fulfils the government's obligation to protect life under the ECHR. Article 2 not only requires that member states not deprive life, but also imposes the positive obligation to, according to Lord Bingham, 'establish a framework of laws, precautions, procedures and means of enforcement which will, to the greatest extent reasonably practicable, protect life' [25]. The participation of coroners in the $\mathrm{VCJD}$ surveillance programme should be understood as contributing to the observance of Article 2; however, it would seem the independence that is deemed necessary for the protection of human life has become an end unto itself - one much divorced from the principle upon which it has been granted.

\section{Conclusion}

The above case provides a vivid illustration of some of the problems that can result for disease surveillance and public health research in jurisdictions where the independence of the death investigation system is given supreme priority. Independence is not an end it itself - it is a means by which such systems are protected from the possibility of undue influence or nefarious interference by central government. It is the independence from central government that is supposed to ensure that death investigation systems can perform their statutory and non-statutory duties. Death investigation systems should be structured in a way that the value of the independence we accord to them in fulfilling their function does not become an impediment to the government's obligation to protect public health and safety.

The independence of death investigation systems from central government is important for a number of reasons. However, since death investigation systems with substantial independence are not directly answerable to central government, they cannot be instructed to participate in any disease surveillance programme regardless of how crucial it is to the protection of human health and safety. Coroners in, for instance, England, Wales, Northern Ireland, and Hong Kong are not required to participate in any public health and safety initiatives owing to their independence from government, nor are they required to provide justification for not doing so. This presents a serious concern for obtaining useful epidemiological data and employing successful programmes to promote and protect public health. Systems currently fielding the possibility of reforming existing death investigation systems (e.g. the Republic of Ireland, India, Singapore, Jamaica) should be wary of valuing independence to such a substantial degree that it can become an impediment to government-led public health and safety initiatives. 


\section{ACKNOWLEDGEMENTS}

C. R. McGowan is partly funded by the Canadian Centennial Scholarship Fund UK. A. M. Viens is funded by the School of Law, Queen Mary, University of London. We thank Dr Shirley Huchcroft, Professor Tony Barnett, and Lisa Graham (of the British Columbia Coroners Service) for their extremely useful comments and suggestions.

\section{DECLARATION OF INTEREST}

None.

\section{REFERENCES}

1. Kung HC, Hanzlick R, Spitler JF. Abstracting data from medical examiner/coroner reports: concordance among abstractors and implications for data reporting. Journal of Forensic Sciences 2001; 46: 1126-1131.

2. Hanzlick R, Parrish G. Coroners and public health. Lancet 1995; 345: 194-195.

3. Graitcer PL, et al. An evaluation of the use of medical examiner data for epidemiologic surveillance. American Journal of Public Health 1987; 77: 1212-1214.

4. Hanzlick R. Medical examiners, coroners, and public health: a review and update. Archives of Pathology and Laboratory Medicine 2006; 130: 1274-1282.

5. Hanzlick R, Parrish RG. The role of medical examiners and coroners in public health surveillance and epidemiologic research. Annual Review of Public Health 1996; 17: 383-409.

6. Lucas SB, et al. The coroner's autopsy: do we deserve better? London: National Confidential Enquiry into Patient Outcome and Death, 2006.

7. The Royal College of Pathologists of Australasia Autopsy Working Party. The decline of the hospital autopsy: a safety and quality issue for healthcare in Australia. Medical Journal of Australia 2004; 180: 281-285.

8. Thayyil S, et al. Prospective parental consent for autopsy research following sudden unexpected childhood deaths: a successful model. Archives of Diseases in Childhood 2009; 94: 354-358.
9. Noah N. Controlling Communicable Disease. Understanding Public Health. Maidenhead: Open University Press, 2006.

10. Nolte KD, et al. Medical examiners, coroners, and biologic terrorism: a guidebook for surveillance and case management. Morbidity and Mortality Weekly Reports. Recommended Reports 2004; 53: 1-27.

11. Ministry of Justice. Statistics on deaths reported to coroners in England and Wales, 2009. London, 2010.

12. Freckelton I. Reforming coronership: international perspectives and contemporary developments. Journal of Law and Medicine 2008; 16: 379-392.

13. The Law Commission (New Zealand). Coroners: a review. Wellington: The Law Commission, 1999.

14. McGowan CR, Viens AM. Reform of the coroner system: a potential public health failure. Journal of Public Health $2010 ; 32$ : 427-430.

15. BBC. Call for tests after sudden death. BBC, E-edition. London: BBC, 2009.

16. Millar T, et al. Tissue and organ donation for research in forensic pathology: the MRC Sudden Death Brain and Tissue Bank. Journal of Pathology 2007; 213: 369-375.

17. Cain V. Report of the task force into illicit narcotic overdose deaths in British Columbia. Victoria, Canada: Office of the Chief Coroner of British Columbia, 1994.

18. Dorries C. Coroners' Courts: A Guide to Law and Practice. Oxford: Oxford University Press, 2004.

19. British Columbia Coroners Service. The role of the coroner in BC. British Columbia Coroners Service, 2008.

20. Office of the Chief Coroner. Office of the Chief Coroner: About the Office. Toronto: Ontario Ministry of Community Safety \& Correctional Services (http://www. mcscs.jus.gov.on.ca/english/office_coroner/about_office/ coroner_what.html). Accessed 27 November 2010.

21. Health Protection Agency. A national human postmortem tissue archive to study the prevalence of abnormal prion protein. London: Health Protection Agency, 2007.

22. Rebello A. Correspondence with the CSEW concerning research into subclinical vCJD. Liverpool: Honorary Secretary of the Coroners' Society of England and Wales, 2007.

23. McGowan CR, Viens AM. Coroners and the obligation to protect public health: the case of the failed UK vCJD study (in press).

24. Phillips MJ, Bridgeman J, Ferguson-Smith M. The BSE Inquiry: Findings and Conclusions. London, 2000.

25. $\mathbf{R}$ (on the application of Middleton) v. West Somerset Coroner [2004] UKHL 10, [2004] 2 All ER 465. 